\title{
A TRAGÉdIA DA LIBERDADE, ANTE-TRAGÉDIA DA CUltura na Filosofia do Dinheiro
}

\author{
Francisco Felizol Marques ${ }^{1}$ \\ (Investigador do Centro de Filosofia da Universidade de Lisboa)
}

A Filosofia do Dinheiro não visa o dinheiro; visa, como já a sua divisão formal nos avisa, desvelar algo no dinheiro, na parte analítica, que o habilita como meio, caminho, método para, na parte sintética, avançar à compreensão do todo, para Simmel, o objecto da filosofia ${ }^{2}$. E esse algo no dinheiro já vai implícito na proposta epistemológica que abre a obra.

Assentando em fundamento, em fixo postulado por provar ${ }^{3}$, a ciência é alvo do cepticismo. Para deste se escudar, Simmel propõe que a ciência, assumindo a contínua incompletude e inexactidão dos seus conteúdos, se constitua como um todo circunstancial e circular de conhecimentos inter-ligados incessantemente mutáveis e corrigíveis ${ }^{4}$, onde cada um é ponto a suportar-se, a valer relativamente a todos os outros ${ }^{5}$. Neste relativismo epistemológico, todo o fenómeno, com o conhecimento a ele correspondente, todo o ponto, independentemente da disciplina onde foi rotulado, está ligado a todos os outros fenómenos. $\mathrm{Na}$ fluida reciprocidade de todos os conhecimentos em incessante progressão, pode a ciência deixar de se (a)

\footnotetext{
1 ffelizol@gmail.com

2 Georg Simmel, Philosophie des Geldes, Gesamtausgabe, Band 6, Frankfurt am Main: Suhrkamp Taschenbuch Wissenschaft, 1989, p. 11.

3 Georg Simmel, Philosophie des Geldes, pp. 98-99.

4 Ibid., p. 116.

5 Ibid., p. 115.
}

Philosophica, 46, Lisboa, 2015, pp. 39-52. 
fundar em petrificações dogmáticas enquanto se livra do corroer céptico ${ }^{6}$. A primeira parte da Filosofia do Dinheiro desvela o dinheiro como modelo deste relativismo epistemológico que a inaugura. Na sua fluidez, no seu ligar tudo a tudo, o dinheiro é, entre sujeitos e objectos, o que o relativismo epistemológico se propõe ser entre os conhecimentos. A história do dinheiro é a do desenvolvimento destes seus atributos.

No princípio, a separação. O sujeito, ao distinguir um objecto ali entre outros, reflecte, toma consciência de si. Mas tal é também um distinguir distância, distância desejo, de si ao objecto ${ }^{7}$ só superada a esforço e renúncia ${ }^{8}$. $\mathrm{O}$ valor resulta desta tensão entre renúncia e desejo, jamais é qualidade do objecto. E este valor, assim relativo, já traz uma troca em cada decisão do sujeito que, para algo obter ou fazer em determinado momento, renuncia a todo o resto, todo o conjunto de suas possibilidades de acção. Tal tensão exteriorizada, envolvendo outros sujeitos e objectos, mais se cava e objectifica um fosso entre sujeitos e objectos. Em troca directa, já o valor está objectivado 9 : pelo menos dois sujeitos e dois objectos, e cada qual a valer relativamente a outros objectos. Até vir o dinheiro intensificar a separação e a objectivação. Instituído como terceiro elemento entre e acima de sujeitos e objectos, o dinheiro regulariza e objectiva essa troca directa que já objectivava o valor. O dinheiro é super-objectivação do valor; o valor em preço de determinado objecto é o valor em preço objectivo da renúncia a todos os outros objectos ${ }^{10}$.

O dinheiro não se impõe sem crédito, sem o crer duma comunidade no seu valor iludidamente substancializado na útil porque inoxidável permanência metálico-preciosa ${ }^{11}$. Mas venha a vulgarização e expansão a tempo e espaço das trocas em dinheiro pedir maior capacidade de divisão e velocidade, mais objectivação, separação que logo o suporte metálico se divide, ou seja, se multiplica em moedas cada vez mais pequenas ${ }^{12}$. A carapaça material é cada vez mais peso, rigidez, estorvo ao fluir do dinheiro ${ }^{13}$ que, na sua aceleração, mutabilidade e atomização gradualmente dela se

\footnotetext{
6 Ibid., pp. 106, 117.

7 Ibid., pp. 38-40.

8 Ibid., pp. 69, 72.

9 Ibid., pp. 35-38, 53.

10 Ibid., p. 123.

11 Ibid., pp. 227-229, 234.

12 Ibid., p. 708.

13 Ibid., p. 158.
} 
liberta até, em forma escritural, ou depois electrónica, se espiritualizar. A representar as relações entre sujeitos, entre objectos, entre sujeitos e objectos, o dinheiro é omnipresente liquidez omnimórfica com atributos divinos de tomar qualquer forma, tão extensível como concentrável a espaço e tempo. Entre e acima de sujeitos e objectos, a ligá-los, o dinheiro, mais que símbolo, materializa quantitativamente a fluidez de relações que constituem a vida humana. É ver as semelhanças com o relativismo epistemológico. Já livre de assentar em subjectividade ou materialidade, o dinheiro é uma imensa nuvem de interacções em constante mutação cuja instável reciprocidade compensando carências com excessos ajuda a dar regularidade, calculabilidade, previsibilidade, eficiência ao quotidiano ${ }^{14}$. Dinheiro é uma irrequieta supra-estância ligadora que dá a constância, a estância que anteriores metafísicas e epistemologias da substância pretendiam garantir com fixado fundamento. Dinheiro é progressiva distanciação de sujeitos e objectos, é gradual objectivação e divisão, tomização, até ao puro fluxo, pura matéria, não forma livre de tomar instantaneamente qualquer forma. Mas começa-se a delinear a tragédia quando o caminho do dinheiro à total atomização e fluidez é também o de sujeitos e objectos. Uma grande objectivação, tão causa como efeito do dinheiro, mas que tem no dinheiro a face mais visível, contamina-se a toda a realidade.

Para se compreender o significado e consequências da grande objectivação, apresente-se sucintamente a visão simmeliana do homem que, só depois formalizada, já segue na Filosofia do Dinheiro. O homem nem é indivíduo, ilhota isolada em sua subjectividade, nem é continente objectivo onde jaz igualizado a todos os outros. Nem ínsula a solo, nem contido em continente, mais que ser, o homem vai, vai ínsula e continente, vai península, vai individualidade, essa ponte em Ponte e Porta (1907) ${ }^{15}$, ou pescoço em $O$ Significado Estético do Rosto $(1901)^{16}$. A tónica no não enquistamento substancial revela solidariedades relativistas: a nossa marginalidade constitutiva vive na margem entre dois pólos sem poder mergulhar num, nem abdicar dos dois: é entre-ser, peninsularidade tão mutilável se apartada do continente objectivo, do outro, como se arrancada da sua ilha de intimidade. Perceber que a história do dinheiro, o seu separar e tomizar, se escreve a par com a separação e tomização do sujeito já deixa antever problemas para esta relacional marginalidade do homem.

14 Ibid., pp. 387, 392, 686, 687.

15 Georg Simmel, "Brücke und Tür", in Aufsätze und Abhandlungen 1909-1918; Gesamtausgabe, Band 12, 2001, pp. 55-61.

16 Georg Simmel, "Die ästhetische Bedeutung des Gesichts", in Aufsätze und Abhandlungen 1901-1908, Gesamtausgabe, Band 7, 1995, pp. 36-48. 
No princípio era o clã (Gens), coesão indivídua sem em si admitir diferença, privação, privacidade, liberdade. Isto até o comerciante estrangeiro $^{17}$, e com ele o dinheiro, começarem a ligar clãs antes isolados. Agora, ligado ao exterior, o clã cresce e já Simmel aplica uma lei só depois formulada na sua Sociologia ${ }^{18}$ : cresce o pequeno grupo, tem este de permitir mais liberdade e diferenciação a seus elementos para sobreviver ${ }^{19}$. O clã abre-se; a figura do indivíduo translada-se para o sujeito. Mas também este, com e como o dinheiro, sofrerá pressões divisoras, flexibilizadoras, libertadoras. Com a divisão do trabalho, o sujeito vê-se desgarrado do produto do seu trabalho afunilado a função e fim mais e mais objectivados e alheios a si, impessoalizados ${ }^{20}$. É agora o sujeito também divíduo mutilado, igualizável a outros divíduos à mesma função num produtivo dividir objectivante, com parte de si separada, objectivada, domesticada, nivelada ${ }^{21}$. Feito funcionário uniforme de atributos funcionais para actividade parcelar, está o sujeito mais e menos livre. Mais livre do grupo, do outro pessoalizado, mais livre do seu produto; mais dependente do todo, de remotas condições económicas, e mais substituível na sua função igualizada.

Em todo este processo, a fórmula evolutiva do dinheiro, dividir para flexibilizar num libertar que tudo liga e aplaina na igualdade da quantia. É de tudo efectivamente desligar, é por aplainar, descartar as qualidades de objectos e sujeitos, que o dinheiro a todos liga na previsibilidade e calculabilidade da monodimensão quantitativa. Com seus atritos qualitativos em quantia aplainados, igualizados, podem sujeitos e objectos, ligar-se e desligar-se, fluir e escorrer.

Não tem este desqualificar domesticador da realidade de ser trágico; toda a civilização por ele sobrevive e progride. Nele assentam o pensar racional $^{22}$, as regras morais abstractas ${ }^{23}$, a representação, a personalidade

17 Georg Simmel, Philosophie des Geldes, pp. 286, 470.

18 Georg Simmel, Soziologie. Untersuchungen über die Formen der Vergesellschaftung; Gesamtausgabe, Band 11, 1992. Leia-se no $2^{\circ}$ capítulo sobre «A determinação quantitativa do grupo» («Die quantitative Bestimmtheit der Gruppe»).

19 Georg Simmel, Philosophie des Geldes, p. 469.

20 Ibid., pp. 393630.

21 Ibid., pp. 393, 394.

22 Ibid., pp. 595, 602.

$23 \quad$ Ibid., p. 650. 
legal jurídica ${ }^{24}$, a ciência, a base comum necessária à paz ${ }^{25}$. Mas o avanço da grande abstracção tem preço difícil de quantificar, logo no empobrecimento redutor e uniformizador em quantia manipulável de toda a complexidade e diferença da vida. A actual proliferação de rankings (dos melhores escritores, pintores, livros, lugares, restaurantes, ao PIB per capita da felicidade e oráculos decimais das agências de rating) exemplifica-o. E num mundo em quantia igualizada, despertam também novas diferenças na imensidão de objectos, com sujeitos incluídos, comparáveis em número. Mais, ainda: o dividir do sujeito não se fica pelo trabalho, progride até à sua intimidade. O uniformizador aplainar da realidade, a libertar os sujeitos de anteriores freios, atritos e atributos também os liberta de ver diferenças, de ver o outro fora deste quadro. Mais e mais os sujeitos objectivamente se diferenciam pelo cálculo, pelo interesse em quantia, o diferenciar mais embrutecido, cego e perigoso. Mais e mais, tende também a reduzir nas suas relações o porquê, o como, o quem e o para quê, ao quanto é em dano e proveito.

O dinheiro que liga e desliga na sua neutralidade objectiva, impessoaliza toda a relação. A subjectiva dádiva pede contra-dádiva, implica uma cadeia pessoal cortada no pagar em dinheiro. Aquele favor ou prenda que prende (daí se preferir dizer "presente") objectiva-se, precisa-se num preço $\mathrm{X}$, alívio de contas saldadas buscado no nosso insistir em pagar um quanto a quem nos diz "não é nada"26. O dinheiro liberta, permite ao sujeito empurrar para a área impessoal suas obrigações e subordinações, limitando abusos pessoalizados $^{27}$. Permite-lhe, mais solto, desligado, mais divíduo descaracterizado, fluir pelo grande grupo descaracterizado, recombinar-se num ligar e desligar que se contamina às relações mais íntimas ${ }^{28}$. Neste terraplenar de atritos subjectivos, também elas ganham a não forma do dinheiro, numa progressiva funcionalidade, uniformidade, diluente de irregularidades emocionais. Vão mais instáveis, voláteis e efémeras, mais leves de se constituírem e desmancharem ao sabor da vertigem de contextos e expectativas, mais líquidas, mais apontadas a fins objectivos, quantitativos, quando não mesmo

24 Ibid., pp. 416, 450.

25 Ibid., pp. 596, 694.

26 Já o contrário, oferecer dinheiro a namorado(a) ou mesmo amigo(a), deixa sempre atrás um inconveniente travo impessoal. Daí que entre namorados e mesmo amigos se prefira trocar presentes a oferecer dinheiro.

27 Georg Simmel, Philosophie des Geldes, pp. 453-456. A subordinação do funcionário ao seu superior limitada à esfera profissional está longe da subordinação pessoal do aprendiz ao mestre, que tanto pode implicar atenções como tabefes e atenções a tabefe.

28 Ibid., pp. 357, 594. 
dinheiro. Tal dinheiro pulula então o divíduo divisível e desprendido, falho de atributos ou carácter, vazio, numa hidrodinâmica de fluir conforme a novidade, a mudança, a moda. Tal já constitui uma mutilação dessa individualidade que também necessita constância em si e no outro.

Novamente por aqui, essa liberdade da quantia, essa liberdade de movimentos que a grande objectivação proporciona acaba, depois de comprometer a irregular riqueza da vida, por ameaçar essa própria liberdade: o sujeito está mais livre, sim, mas por estar tão mais dependente, preso dessa igualização que lhe invade a realidade. E o nivelar, o aplainar deste processo prossegue a impor à própria vida o ritmo repetido da máquina ${ }^{29}$. Simmel detecta nesse descartar de atritos e irregularidades, nessa igualdade que se quer eternizar pelo tempo em simetria simplificadora o mesmo espírito de regular e igualizar dos despotismos e utopias ${ }^{30}$ de cidades em forma geométrica concêntrica. A obsessão da regularidade, da permanência, da igualdade pelo tempo é simetria centrípeta que violenta todos os particulares pontos a um único, na eternização funerária de pirâmide aprumada a vértice.

Mas não se penetra nessa liberdade, tão promovida como tolhida pela grande objectivação, sem se passar pela propriedade e pelo fim, no sentido de propósito.

Tal o ser, o saber, ou o valor, a propriedade em Simmel é-o relacionalmente: implica acção que só o é experimentando reacção, resistência. Propriedade é acção sobre objecto que se lhe objecta, resiste, opõe, dando-lhe onde pôr, onde exercer positividade. Que os objectos têm atributos, propriedades que resistem ao pôr do sujeito proprietário, este nunca pode possuir totalmente um objecto, dispor dele ilimitadamente, transformá-lo no que lhe aprouver ${ }^{31}$. Só a pura liquidez informe, vazia de conteúdo e propriedades, se dá a toda a forma ${ }^{32}$. Sem resistir à acção do proprietário, imediatamente transfigurável em qualquer forma, o dinheiro não é propriedade.

Avançando meio a meio pela realidade que lhe resiste, em cadeia teleológica, o homem evolui, progride a um fim ${ }^{33}$. O melhor para avançar nesta cadeia é, numa intermitente inversão teleológica, fazer do próximo meio fim ${ }^{34}$. Volta-se à questão já tratada na propriedade: sem um agir com propriedade, sem um agir positivo, sem um avançar de meio a meio, não

\footnotetext{
Ibid., pp. 685-688.

$30 \quad$ Ibid., p. 682.

31 Ibid., p. 444.

32 Ibid., pp. 436, 437.

33 Ibid., pp. 257-259.

34 Ibid., p. 297.
} 
se tem um fim. E novamente o dinheiro, sem opor qualquer resistência, destituído de propriedades que o façam propriedade, não pode também ser um fim. Antes, a poder tomar qualquer forma, é o meio dos meios ${ }^{35}$, inserível em qualquer cadeia teleológica. Que, na inversão teleológica, tomamos por fim o próximo meio, facilmente fazemos deste não fim um $\mathrm{fim}^{36}$. E pondo como fim esse dinheiro vazo de resistências, propriedade e fim, fácil ele se entroniza como fim absoluto, extinguindo os outros fins. O não fim elevado a fim dos fins resulta no fim dos fins, no termo de outro qualquer propósito. Se já de si a liberdade que o dinheiro confere não traz por si qualquer positividade, agrava-se o cenário quando, dela encantados, expulsamos toda a positividade. A liberdade endinheirada, pura liberdade negativa de não agir, pôr ou criar, é liberdade de movimentos; sem ver condicionalismos, passado e futuro, vive do instante, se devora no seu vazio, segue entediada à procura do que mais esvaziar.

Siga-se ao bestiário de trágicas alienações libertas à negatividade do dinheiro, livres por livres de propriedade e fim. O liberto ao dinheiro, o que por dinheiro troca todas as suas propriedades, já cheio de pura liquidez, já sem atrito, positividade e fim, mutilando sua individualidade, já tudo pode e já. $\mathrm{O}$ avarento ${ }^{37}$ acumula pura potência, pura possibilidade, sem nunca se atrever a usá-la, sem nunca agir, sem propriedade e fim. No pólo oposto, o esbanjador ${ }^{38}$, que, encandeado do prazer de adquirir objectos atrás de objectos, persegue o seu (não) fim, um arbitrário e sempre efémero contínuo adquirir; nem propriedade, nem fim. O blasé $e^{39}$ reconhece no quotidiano esse todo feito quantia, onde, tudo igualizável a dinheiro, lhe parece sem valor. Busca então, sôfrego, a diferença, a novidade, um instante condensado de prazer ou sofrimento, busca chegar onde o dinheiro ainda não chegou, vulgarizou, maculou. Com a regular irrequietude do esbanjador, saltita de excitação em excitação diferenciadora que, fruto de Tântalo, logo a seus olhos se indiferencia, vulgariza. Novamente, nem uso em propriedade, nem fim.

A figura do blasé é paradigmática do que Simmel, a escrever na Berlim de 1900, vê estender-se pelo quotidiano e aqui se chama modernidade blasée. Mas, para tal se perceber, tem agora de se tratar da divisão, liquefacção, libertação, afastamento dos objectos que, paralelas às do dinheiro

\footnotetext{
35 Ibid.p. 677.

36 Ibid., p. 298.

37 Ibid., pp. 308-321.

38 Ibid., pp. 321-328.

39 Ibid., pp. 334-337.
} 
e dos sujeitos, formou, geração após geração, uma cultura objectiva ${ }^{40}$ cuja imensidão e complexidade crescentes se fazem impenetráveis ao sujeito. Pouco, senão nada, sabe este dos objectos que lhe povoam o quotidiano. De onde veio esta cadeira, como foi feita, por que processo passou? Também os objectos se impessoalizam, mais são produto objectivado duma crescente especialização e objectivação e mais o sujeito, deles rodeado, os estranha ${ }^{41}$ num fosso que não pára de crescer. A progressão no conhecimento, também ela um separar e objectivar, tão mais disponibiliza ao sujeito mais objectos, the multiplica as possibilidades, como, tal a sua distância e tamanho crescentes, mais os torna inacessíveis de se poderem usar como propriedade. Mais diferenciados, autónomos, mais e mais estes objectos nos chegam e vão de moda e novidade em torrente líquida de velocidade e pulverização crescentes. Inundado de tantos, tão efémeros, distos e estranhos objectos e mais deles dependente, mais o homem se vê incapaz de os possuir como propriedade, mais por eles se deixa possuir. Há escravidão nessa liberdade de chegar a todos os objectos. Menos o sujeito consegue abarcar, mais lhe cresce um vácuo a sorver sôfrego mais superficialidades, instantaneidades, fragmentos, e mais a isto preso o sujeito se faz essa superficialidade, instantaneidade, fragmentação quotidianas de que pretende escapar. Que a angústia aperta, o homem tenta vislumbrar, na torrente, um fundamento último. Se o pensa encontrar na ciência, na auto-glorificação de domar a natureza ${ }^{42}$, novo deslumbrar no meio posto como fim. Não desconfia como esse mitificado "domínio" da natureza mais o domina nos moldes dessa grande objectivação que mais lhe dita o seu consumir, o seu pensar, o seu viver, mais o escraviza a suas futilidades, mais o pulveriza.

Aí na fragmentação multiplicadora, na vertigem da novidade por novidade, um procurar em forçada agitação quaisquer efémeras excitações artificiadas $^{43}$, um uniformizador fugir da uniformização, do vazio e da indiferença, a modernidade blasée. A torrente não pode deixar de atiçar a nostalgia da permanência, mas, em aceleração blasée, num reinventar recombinatório a reciclar em série contínua estilos e gostos passados, novas e novas necessidades cada vez mais divididas, específicas e elaboradas. Uma modernidade à moda esvazia-se de propriedade e fim, apostada num diferenciar blasé, que, formal, mais vazo de conteúdo, se fada a reforçar a imperante igualização, na fórmula do ser diferente sem positividade ou propósito fora do ser diferente.

$40 \quad$ Ibid., pp. 620-626.

${ }^{41}$ Ibid., pp. 621, 636, 637.

42 Ibid., pp. 672-674.

$43 \quad$ Ibid., pp. 336, 337. 
É altura de tentar perceber em que poderá consistir para Simmel a liberdade efectiva, porque positiva. Tal o conhecimento, o ser, o valor, a propriedade, a liberdade em Simmel implica relação ${ }^{44}$. Liberdade é libertar de obrigações e conteúdos para prender a outros. Liberdade implica uma sucessão de não liberdades, de resistências, de renúncias, de meios, que confiram positividade à individualidade, permitindo-lhe pôr, criar com e para o outro em direcção a um fim individual nunca desligável do outro. A liberdade só por não liberdades tem positividade, implica pôr com oposição, agir com propriedade a um fim individual.

Em $O$ conceito e a tragédia da cultura $(1911)^{45}$, o homem vive de criar formas, suas produções tecnológicas, políticas, religiosas sempre fixações, limitações. É com tais fixações descontínuas que o homem tenta apreender a matéria viva corrente, ilimitada, contínua e informe, ligar o mundo numa unidade inteligível. Mas, tragédia da cultura: criadas, estas formas são já passadas, já se despojam dos conteúdos e do propósito por que as criámos; falta-lhes a organicidade das formas vivas que subsistem mudando em continuidade e unidade. Na deriva dos incontinentes, as nossas rígidas criações, o oposto da vida, da matéria que pretendem abarcar, só temporariamente contêm os seus conteúdos; logo se esvaziam, desvivificam, estranham a seus conteúdos primordiais e ao homem. Ou se dissolvem na matéria viva a correr ou enquistam numa petrificação dogmática feita fim autónomo em si que, desgarrado do nosso, prende, paralisa, violenta o homem. A tragédia é este contínuo esbarrar e progredir do homem na rigidez e incontinência das suas criações.

Na Filosofia do Dinheiro, o dinheiro, a não forma de tomar toda a forma é imperfeita imitação da matéria viva, pois que tudo reduz à única dimensão quantitativa. Desde a original separação, entre sujeito e objecto, a progressiva atomização, libertação, fluidificação do dinheiro foi acompanhada por objectos e sujeitos numa explosão global e em expansão: os objectos, mais e mais fraccionados, mais e mais se afastam dos sujeitos também mais fraccionados e distantes entre si. Tal tomização que atomiza, tal dividir, não multiplica as formas sem as encurtar a tempo e espaço, sem as aproximar mais e mais da não forma, da matéria. $\mathrm{O}$ dinheiro fragmenta e acelera de remoinho as partículas a girarem sobre si, dá-lhes sua hidrodinâmica. Sujeitos e objectos mais próximos da não forma dinheiro, aproximam-se, na maior fluidez e liberdade de tomar várias formas, da matéria líquida e indiferenciada. É por tal que o permanente suceder das formas de

\footnotetext{
$44 \quad$ Ibid., p. 397.

45 Georg Simmel, "Der Begriff und die Tragödie der Kultur" in Hauptprobleme der Philosophie, Philosophische Kultur, Gesamtausgabe, Band 14, 1996, pp. 385-416.
} 
A Tragédia da Cultura, com o consequente afastar e desadequar, já estát6, e em versão acelerada, nessa cultura objectiva que, mais e mais estranha e nos foge na Filosofia do Dinheiro. Encarnando a grande objectivação, o dinheiro, mais que meio e lubrificador da troca, lubrifica essas formas sucedidas em tragédia da cultura; enforma-as, deforma-as mais curtas, efémeras e esvaziáveis de seu conteúdo para, na torrente, continuamente se substituírem pelas seguintes ainda mais fragmentadas. Ainda sem formalizar a tragédia da cultura, já Simmel se concentrava na aceleração do ritmo de vida, na partição, na multiplicação, na aceleração da sucessão de formas que com o dinheiro vêm; já via o distanciamento e tamanho crescentes da cultura objectiva como um lubrificar da tragédia da cultura.

E a, atrás tratada, resposta blasée, senão espasmo subjectivo, à grande objectivação moderna mais ajuda a agravá-la, acelerando a tragédia da cultura. Aquele contínuo buscar novidades, necessidades, mais objectos produtos dessa cultura objectiva, só pode representar mais tomização, mais formas tão mais vazias quanto efémeras. Estas, de tão continuamente aceleradas, mais impossibilitam o já impossível de abarcar ${ }^{47}$. Não é difícil reconhecer tal descrição no nosso quotidiano. Todo este fluir em torrente novidade, a pedir constante adaptação, transformação, mudança se apanha nas formas fluídas e hidrodinâmicas dos objectos, cada vez mais gadgets, nas curvas cool e sexy de automóveis, edifícios. Não pode admirar que o homem íntegro, de boas contas, o anterior repositório de valores burgueses, agora nos pareça um cinza enfadonho a gritar fixidez, atrito, resistência ao fluir. O modelo é agora o dinâmico empreendedor de projectos, tão activo quão redondo, informe, infinitamente divisível de poder tomar qualquer forma ou upgrade reciclável, fluido para nadar na fluidez. Objectos e sujeitos que aparentem rigidez e inflexibilidade cansam, pesam, causam repulsa por sua fixidez carregada de certeza. É remodelar-lhes a imagem com mais cor, movimento, suavidade, flexibilidade e menos peso, calorias, seriedade, precisão nos contornos. É por tal que a imagem dos bancos, antes carregada com a burguesa respeitabilidade, solidez e segurança dos tons sóbrios, agora grita peso, rigidez, cansaço. Aos bordeaux, azuis e verdes carregados tem de se lhes impregnar uma cosmética de vazio esbranquiçado que resulta em rosa, laranja, azul e verde claros. Vai nesta leveza mais aquática, igualizada, vazia, flexível e cool um translúcido que já aponta a uma transparência multiforme, moldável a tudo. Não pode também admirar, neste contexto, a quase sacralização da transparência, subida a modelo universal. Onde tudo à volta mais e mais se fracciona e igualiza, se molda a contexto

46 Georg Simmel, "Der Begriff und die Tragödie der Kultur", pp. 408, 409, 412-415.

47 Ibid., pp. 414-416. 
e circunstância, têm sujeitos e objectos de ganhar essa leveza da transparência sem atrito, nudez publicitária do nada ter a esconder concordante, no seu esvaziar, com o cada vez menos ter para esconder. O não transparente, aquele que não atende telefonemas, não telefona de número identificado, não tem facebook, é algo não imediatamente digerível, mal perto de terror, impureza resistente ao fluído esbranquiçar igualizador do mundo. Os sujeitos divíduos flexíveis a fluir por objectos parcelados mais, com eles, se partem e flexibilizam. Uma constante sofreguidão de novidade, fabricada dum emparcelar, especificar e recombinar, atirada a um prazer a prazo que não comprometa, não prenda, mais novidade, moda, efemeridade pede. E já a pressão blasé da novidade engendra, exige novos e novos tipos de relacionamento íntimo: que uma flexibilidade e mobilidade de novos e novos parceiros, cenários, apetrechos, próteses em empapada recombinação, continuamente alimente a devoradora fome de mais variedade, mais quantidade de experiências. E já com tal fluir, se impregna no senso comum um moralizante dever de "experimentar de tudo o mais possível". Novidade, excitação, blasé. Inventam-se novas cozinhas numa fusão de técnicas, chefes, ingredientes. Singra até a refeição de tapa e petisco que pulveriza uma refeição em muitas ${ }^{48}$. O mesmo requentado receituário de fusão recombinada chega na fome de novidade e liberdade self-service à religião, à política, à "filosofia" fondue de retalhar e mergulhar em auto-ajuda. Mais que o espírito de todo um tempo, de toda uma modernidade, depois pós-modernidade (e o termo já leva tão pouco dessa repetição, desse esforço diferenciador falhado) à moda, detecta-se aqui um feedback positivo onde as consequências mais impulsionam o próprio processo.

Está-se agora em condições de expor a tragédia da liberdade. No agravar o distanciamento da cultura objectiva que se traduz no agravar da tragédia da cultura, no liquefazer das formas, do outro, da realidade, ameaça-se a individualidade peninsular. Esta, tal as formas em tragédia da cultura, pode deixar-se enquistar ou dissolver. Está cada vez mais perto de se deixar cair nestes dois pólos de alienação: ou se acopla a uma forma enquistada, cega autonomia, que, estranha a si, a empurra para uma dissolução no continente objectivo; ou se descarta das formas, objectos e sujeitos, se isola numa pretendida insularidade indivídua, nadando tão livre quão negativamente no nada, na dissolvente corrente da matéria ${ }^{49}$. Que a margem se estreita entre estes dois pólos, de extrema alienação objectiva

48 Também no reduzir os alimentos à sua composição em hidratos e calorias que os permita comparar se tem a fórmula dinheiro do parcelar para quantificar e depois prescrever um quanto a consumir.

49 Georg Simmel, ’Der Begriff und die Tragödie der Kultur", p. 389. 
e subjectiva, resta ao homem permanecer marginal, preservar sua marginalidade. Só na margem pode a individualidade continuar peninsularidade relacional, continuar sujeito com objecto, com acção que constitua propriedade e fim. Só na margem, aproveitando as formas objectivas não para nelas se paralisar mas para por elas progredir, fazer seu caminho a um fim, o homem não torna trágica esta tragédia.

Toda a tragédia tem pathos a sofrer e moira a cumprir. A moira na tragédia da liberdade está na exigência de um contínuo pathos duma não liberdade à não liberdade seguinte, onde, rumo a seu fim individual, a individualidade continuamente tem de zelar para não se mutilar, não cair num dos pólos de alienação, subjectivo ou objectivo. Mas esta tragédia da liberdade não tem de ser trágica. Este pathos a sofrer numa moira continuamente por cumprir tem duas atenuantes. Primeiro, a satisfação a cada não liberdade superada é um tónico a aproveitar para a próxima superação. Segundo, o próprio dinheiro, a própria incarnação dessa grande objectivação, que nos estreita a banda entre os dois pólos de alienação, pode ser usado neste fazer caminho onde, sem nunca abdicarmos do esforço, da forma, doutros meios que não o dinheiro, da não liberdade, podemos pôr e criar com e para o outro, rumando a nosso fim individual, nunca fixo, nunca alcançável, sempre um caminhar connosco.

Efectivamente, o dinheiro, no centro da grande objectivação, tomização, liquefacção da realidade, no fulcro da tragédia da liberdade, não é para Simmel diabolização a banir. Como se viu atrás, mesmo em autarcia, já em nós se manifesta, em germe, o dinheiro no mais inocente decidir renunciar a fazer isto para fazer aquilo, opção que carrega uma troca entre pelo menos duas valorizações. O dinheiro repete-se, materializa imperfeita porque unidimensionalmente as relações de vida que, de nós, fluem para o exterior, nos ligam aos outros. Sendo algo radicado na existência humana, não adianta diabolizar o dinheiro, atribuir-lhe causa e culpa de todos os males e sonhar com amanhãs sem dinheiro, cobiça, dívidas. Assim como tão escravo da moda é o dandy como o anti-moda, rejeitar o dinheiro pode também resultar noutra endinheirada alienação, por exemplo, num acumular de créditos espirituais. Qualquer mudança estará sempre no modo como se encara, como se lida com o dinheiro. A sua impessoalidade, propagada em todo o processo de objectivação, pode conferir uma positividade bem além da mera liberdade de movimentos. Com dinheiro, o sujeito não só pode proteger melhor a sua intimidade ${ }^{50}$, como vê incomensuravelmente aumentadas as suas possibilidades. Resta que, ao invés de se deixar encandear nelas ou directamente no dinheiro (como as alienações do esbanjador

50 Georg Simmel, Philosophie des Geldes, pp. 652-654. 
e blasé e a alienação do avarento exemplificam), o sujeito as use para um qualitativo refinamento pessoal, um enriquecimento da individualidade ${ }^{51}$. A possibilidade de escapar aos dois pólos de alienação pode assim também estar no próprio dinheiro, no dinheiro usado como meio, meio a superar resistências, formas de não liberdade, no caminho a um fim individual com e para os outros entre os dois pólos de alienação. Este multiplicar das nossas possibilidades, esta liberdade proporcionada pelo dinheiro é indispensável, mas nunca suficiente, a um agir positivo. Toda a questão se enquadra no deixarmos ou não que o dinheiro, e suas facilidades, nos encandeie, nos despoje de fim por o entronizarmos como fim, nos mutile a nossa individualidade.

Assim, Simmel propõe o relativismo para, na contínua interacção e correcção entre os diferentes conteúdos de conhecimento, afastar o enquistamento dogmático e o cepticismo; assim, Simmel propõe que a individualidade, num contínuo esforço de progressão a seu fim usando e seleccionando as formas, os meios, o outro, se afaste dos dois pólos de alienação, enquistador ou dissolvente.

É voltar à estrutura da Filosofia do Dinheiro para se perceber o que fazer com o dinheiro. Encará-lo e prepará-lo como meio para depois assim o usar a um fim dele autónomo. Ou se mantém o dinheiro como meio a promover a diversidade da vida, ou, caído a fim, o dinheiro seca todos os fins, toda a riqueza viva.

$51 \quad$ Ibid., p. 654. 
RESUMO

Na Filosofia do Dinheiro (1900), o dinheiro é uma contínua atomização, libertação e fluidificação até poder tomar qualquer forma, igualizando em quantia todas as qualidades dos elementos que relaciona. Este processo deu-se também: nos objectos, mais e mais efémeros e libertos do homem, constituindo uma cultura objectiva que dele se afasta; e nos sujeitos que, em progressiva tomização, alcançam uma liberdade negativa destituída de propriedade e fim. Tal ameaça a individualidade humana entre o sujeito isolado na sua subjectividade e o sujeito aglutinado em continente objectivo. Em 1911, Simmel descreverá a vida humana como tragédia da cultura, ao tentar conter a matéria viva criando sucessivamente formas que, criadas, imediatamente se esvaziam de conteúdos. Tal já segue na $F i$ losofia do Dinheiro, como tragédia da liberdade. Só usando o dinheiro como meio, só agindo em liberdade positiva, ultrapassando sucessivas resistências, formas de não-liberdade, podemos caminhar a nosso fim individual.

Palavras-chave: Georg Simmel - liberdade - dinheiro - individual - tragédia

\begin{abstract}
In Philosophy of Money (1900), money is a permanent splitting liberation and fluidification, until it takes any form through equalizing in quantity all qualities it bounds to. This process also happens: in objects, more and more ephemeral and independent from man, leading to an objective culture that gets farther away; and in subjects, exposed to a continuing splitting process, thereby gaining a negative freedom with no properties and purpose. This menaces man's individuality which is neither an isolated subjectivity nor an agglutinated objectivity. In 1911, Simmel describes human life as a tragedy of culture, an attempt to contain the living matter creating successive forms that, once created, begin to drain its contents. This view was already acknowledged in the Philosophy of Money as the tragedy of freedom. By only using money as a means, acting on positive freedom, we overcome successive resistances (non-freedom forms) and advance to our individual purpose.
\end{abstract}

Key-words: Georg Simmel - freedom - money - individuality - tragedy 